\title{
Diabetes Mellitus Management, Needs Reconsideration
}

\author{
Dr Avinash Shankar ${ }^{1 *}$, Dr Amresh Shankar², Dr Anuradha Shankar ${ }^{3}$ \\ ${ }^{l} M B B S(M G I M S) ; M D$ (Internal Medicine); DNB(E\&M); PhD, Postgraduate in Endocrinology \& Metabolism \\ (AIIMS Delhi), Chairman, National Institute of Health \& Research, Warisaliganj (Nawada) Bihar India \\ ${ }^{2}$ BAMS(BRABU); MHA, Director (Hon), Aarogyam Punarjeevan, Ram Bhawan, Ara Garden Road, Jagdeopath, \\ Baily Road, Patna 14, India \\ ${ }^{3} B A M S$ (BRABU), Ex Director, Centre for Indigenous Medicine \& Research, Senior Research Fellow, Regional \\ Institute of Ayurveda, Itanagar, Arunachal Pradesh, India
}

*Corresponding Author: Dr Avinash Shankar, PhD Postgraduate in Endocrinology \& Metabolism (AIIMS Delhi), Chairman, National Institute of Health \& Research, Warisaliganj (Nawada) Bihar India. Email: dravinashshankar@gmail.com

\begin{abstract}
Diabetes mellitus, progressively increasing worldwide and India is considered as Diabetes capital of the world with a projected incidence of 109 million by 2035, as this disease of luxury is affecting even down trodden daily wage earner hard workers and both sexes equally due to emergence of toxic non-nutrients in the diet, drinks and oil solely caused by rampant use of fertilizer, chemicals, pesticides, hormones, preservatives and processing.

In addition, patients show increased tolerability to high blood sugar level and create suspicion regarding etio pathogenesis of hyperglycaemia

Material \& Method: In present study 20,000 population of 20 Dalit hamlets and 10 villages of Nawada district aged > 35 yrs screened for blood sugar, clinical examination and patients of Diabetes mellitus attending Institute of Applied Endocrinology and Aarogyam Punarjeevan Patna 14

Result: Study reveals adjuvant hepatogogue with antidiabetic drug and dietary restriction check circadian variation of blood sugar and ensure blood sugar bioregulation with continued tapering of anti-diabetic dose without any consequent sequel or adversity. Toxic non-nutrient dietary constituents suppress secretion and production of GLP 1 in the L cells of mucosal lining of the small intestine and stimulate production of Dipeptidyl peptidase 4 which further increases GPL 1 degradation resulting in decrease in volume of insulin secreting $\beta$ cells in the pancreas and decline in insulin release manifesting as hyperglycemia while altered hepatic profile and better glycemic control on adjunction of hepatogogue with antidiabetic drug and restricted first diet to 100 calories suggest hyperglycaemia as a combined effect of hepatic and pancreatic dysfunction .
\end{abstract}

Conclusion: Thus in present scenario prior to advocation of anti diabetic drugs in newly detected cases and alteration in dose of antidiabetic drugs in old diabetics Patients must be reassessed after due change in-

- $\quad$ Diet, life style, stress redressal

- Timely advocation of drugs and diet to ensure blood sugar bioregulation.

Keywords: Glycemic control, bioregulation, circadian variation, dysfunction, stress redressal

\section{INTRODUCTION}

Globally prevalence of diabetes mellitus increasing progressively and quadrupled in past three decades affecting presently 1 in 11 adult world wide establishing diabetes as $7^{\text {th }}$ major cause of death. Asia is a major area of the rapidly emerging type 2 diabetes mellitus global epidemic, India was second to China in prevalence of Diabetes mellitus until recent time but now India is at the top global in global prevalence of Diabetes mellitus ${ }^{(1,2,3,4)}$
The latest estimates show a global prevalence of 382 million people with diabetes in 2013, expected to rise to 592 million by 2035 . diabetes can lead to multisystem complications of microvascular endpoints, including retinopathy, nephropathy and neuropathy, and macrovascular endpoints including ischaemic heart disease, stroke and peripheral vascular disease

Diabetes currently affects more than 62 million Indians, which is more than $7.1 \%$ of the adult 
population. Nearly 1 million Indians die due to diabetes every year ${ }^{(5,6,7,8)}$

Diabetes mellitus a diseases of luxury is also affecting daily wage earner poor community without any discrimination which may be attributed to changed life style, dietary habits, declined nutritional value, increased nonnutritive constituent and emergence of some toxic enzymes or molecule in the commonly consumed food, vegetables, fruits, oil, condiment and drinks due to heavy miss use of fertilizers, chemicals, pesticides and hormones to grow and yield more. ${ }^{(9,10,11)}$

In addition, Insulin supplementation was used to be some most proper therapeutics but these days the trend of multiple dose of Insulin or insulin regulated dose by insulin pump is quite in vogue but patients becoming non-responsive or resistant even to Insulin supplementation. ${ }^{(12,13,14)}$

Earlier patients with post prandial blood sugar > $400 \mathrm{mg}$ and fasting > $300 \mathrm{mg}[5,6]$ were very less and was considered a dreaded state of diabetes mellitus and usually present the clinician with various complication or in unconscious or semiconscious statue, but these days patients even with fasting blood sugar > $400 \mathrm{mg}$ came walking and narrate their complaints of their own with comfort and ease.

In Diabetes mellitus focus must be on dietary restriction rather than poly molecule anti diabetic therapy as circadian variation of blood sugar level will pose threat to human vitality. Thus, creates a suspicion of existence of any supplementary cause in addition to pancreatic and usually present the clinician with various complication or in unconscious or semiconscious state, but these days patients even with fasting blood sugar $>400 \mathrm{mg}$ came walking and narrate their complaints of their own with comfort and ease $^{(15,16,17,18)}$

IDF recommendations for a healthy diet for the general population

Choosing water, coffee or tea instead of fruit juice, soda, or other sugar sweetened beverages.

Eating at least three servings of vegetable every day, including green leafy vegetables.

Eating up to three servings of fresh fruit every day.

Choosing nuts, a piece of fresh fruit, or unsweetened yoghurt for a snack.

Limiting alcohol intake to a maximum of two standard drinks per day.
Choosing lean cuts of white meat, poultry or seafood instead of red or processed meat.

Choosing peanut butter instead of chocolate spread or jam.

Choosing whole-grain bread, rice, or pasta instead of white bread, rice, or pasta.

Choosing unsaturated fats (olive oil, canola oil, corn oil, or sunflower oil) instead of saturated fats (butter, ghee, animal fat, coconut oil or palm oil.

\section{OBJECTIVE OF STUDY}

To asses the role of dietary control, first oral diet and hepatogogue co administration with Oral hypoglycaemic and Insulin supplementation in blood sugar bioregulation

\section{Materials AND Method}

Design of Study: Controlled comparative evaluation of hepatic function improvement on therapeutic outcome of Diabetes mellitus management.

In Diabetes mellitus focus must be on dietary restriction rather than poly molecule anti diabetic therapy as circadian variation of blood sugar level will pose threat to human vitality. Thus creates a suspicion of existence of any supplementary cause in addition to pancreatic $\beta$ cell dysfunction as a cause of the present hyperglycaemia. Hence to ascertain the variation in etio pathogenesis of hyperglycaemia, a study was planned to ascertain whether hepatic mechanism is also responsible for the present hyperglycaemic syndrome.

\section{MATERial}

To asses changing pattern of Diabetes mellitus 10 hamlets and 20 villages of Nawada district were randomly evaluated for urine sugar and blood sugar both fasting and $\mathrm{pp}$ in suspected cases of age $>20$ yrs of either sex. In addition, patients attending at Institute Of Applied Endocrinology And Aarogyam Punarjeevan, Patna 14, Bihar were considered and patients with Diabetic sequelae were excluded from the present study.

\section{METHOD}

Each person showing positive either for urine sugar, blood sugar or both were thoroughly interrogated for history of increased frequency of urine, increased thirst, increased appetite, lethargy, tingling numbness, recurrent boils, nonhealing wound, itching, general debility, exertional dyspnoea, sexual debility, personal habit, dietary habit, schedule of diet, nature of work, duration of work and any family history of 
Diabetes mellitus, investigated for fasting and post prandiol blood sugar, urine sugar hematological parameters, hepatic profile and renal profile. The investigation is repeated after 3 and 6 months of therapy to establish the etiopathogenesis and therapeutic outcome.

Among the hospital detected patients either fresh or old cases taking treatment (Oral hypoglycemic or Insulin Supplement Or both) with dietary restriction and presenting with varied glycemic level were considered and divided in to two groups i.e., Both Group

Diet: Carbohydrate restricted diet with first oral intake restricted to 100 calories.

Continuing Oral hypoglycaemic or Insulin in old cases while fresh cases were advised accordingly.

Group A (Study group): Hepatogogue both oral and parenteral

\section{Group B (Control group): Placebo}

Both group patients were given a follow up card and Glucostix to evaluate their urine for sugar, in case of manifestation like forgetfulness, lethargy, semi consciousness or complete absence of sugar in urine, attend the DRC for estimation of blood sugar, continuing anti diabetics (OHA or Insulin supplement) were tapered down with maintained normoglycemic level.

Initially patients were followed up weekly for 6 months, every $15^{\text {th }}$ day for 1 year and monthly for next 1 year to adjudge the therapeutic outcome and disease sequel.

\section{OBSERVATIONS}

Selected patients were of age group 30 - 65 yrs and out of all 196(16.2\%) cases were of age $<35$ yrs while $130(10.7 \%)$ were of age $>60$ yrs (Table-1). male: female composition was 729:477 (Fig-1)

Table1. Distribution of patients as per age \& sex

\begin{tabular}{|l|l|l|l|}
\hline \multirow{2}{*}{$\begin{array}{l}\text { Age Group } \\
\text { (In years) }\end{array}$} & \multicolumn{3}{|l|}{ Number of Patients } \\
\cline { 2 - 4 } & Male & Female & Total \\
\hline $30-35$ & 109 & 87 & 196 \\
\hline $35-40$ & 117 & 71 & 188 \\
\hline $40-45$ & 97 & 62 & 139 \\
\hline $45-50$ & 104 & 69 & 173 \\
\hline $50-55$ & 115 & 74 & 189 \\
\hline $55-60$ & 103 & 68 & 171 \\
\hline $60-65$ & 84 & 46 & 130 \\
\hline Total & 729 & 477 & 1206 \\
\hline
\end{tabular}

\section{Pie diagram showing male female composition}

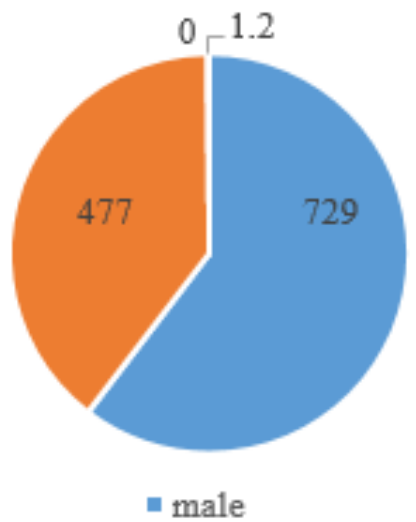

Figure1. Pie diagram showing showing male: female composition

675 and 531 cases were of new and old cases respectively (Fig2) 


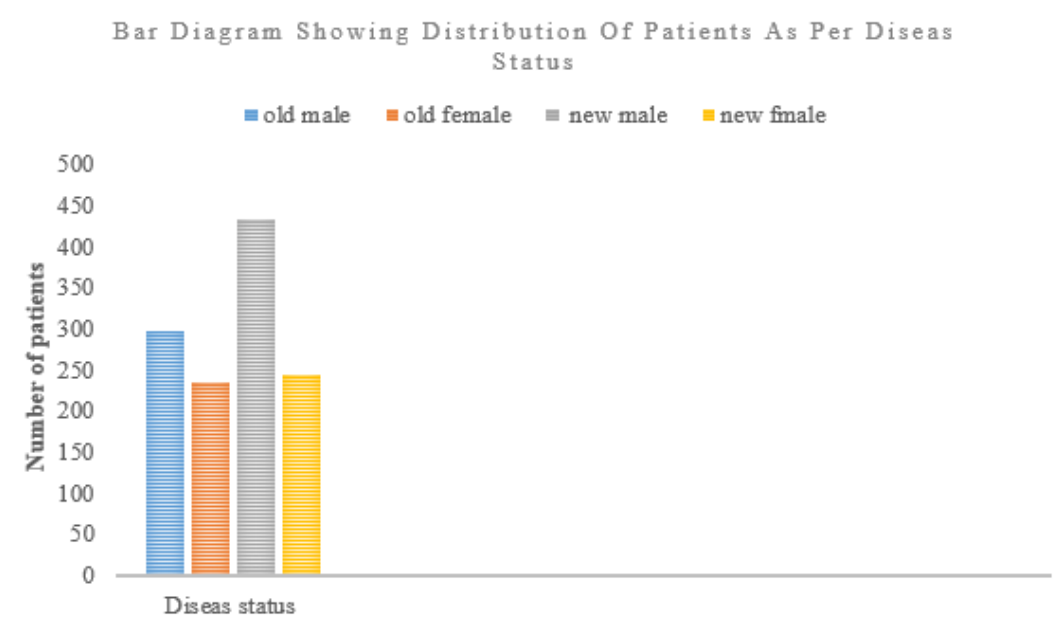

Figure2. Bar diagram showing distribution of patients as per disease status

Out of all $27.9 \%$ were of middle class income group and $42.6 \%$ were daily wage earner (Table-2)

Table2. Distribution of Patients as Per Economic Status

\begin{tabular}{|l|l|}
\hline Income Group & Number of Patients \\
\hline Below poverty line (BPL) & 212 \\
\hline Daily earner & 514 \\
\hline Low Income & 144 \\
\hline Middle Class & 336 \\
\hline
\end{tabular}

$34.8 \%$ were leading sedentary life while $25.3 \%$ were hard workers (Table-3).

Table3. Distribution of patients as per their nature of work

\begin{tabular}{|l|l|}
\hline Nature of Work & Number of Patients \\
\hline Sedentary Exertion & 384 \\
\hline Mild & 119 \\
\hline Moderate & 299 \\
\hline Severe & 99 \\
\hline Hard Worker & 305 \\
\hline
\end{tabular}

$68.32 \%$ were vegetarian and rest $31.68 \%$ were non vegetarian, $75 \%$ weretaking two times meal while $25 \%$ were consuming divided four meals(Table-4)

Table4. Distribution of patients as per dietary habit and schedule

\begin{tabular}{|l|l|}
\hline Particulars & Number of Patients \\
\hline Vegetarian & 824 \\
\hline Non vegetarian & 382 \\
\hline Two heavy meals & 904 \\
\hline Four divided meals & 302 \\
\hline
\end{tabular}

$33.33 \%$ were stressed and $7.89 \%$ were non stressed and non addict (Table-5)

Table5. Distribution of patients as per personal status

\begin{tabular}{|l|l|}
\hline Personal Habits & Number of Patients \\
\hline Alcoholic & 112 \\
\hline Toddy & 396 \\
\hline Multi narcotics & 201 \\
\hline Stressed & 402 \\
\hline No habit non stressed & 095 \\
\hline
\end{tabular}

$40.8 \%$ Were with Normal ideal body weight while $18.2 \%$ with <IBW and $41 \%$ with $>$ IBW(obesity) (Table-6) 
Diabetes Mellitus Management, Needs Reconsideration

Table6. Distribution of patients as per body weight

\begin{tabular}{|c|c|c|c|}
\hline \multirow{2}{*}{$\begin{array}{c}\text { Age Group } \\
\text { (In years) }\end{array}$} & \multicolumn{3}{|c|}{ Number of Patients } \\
\cline { 2 - 4 } & \multicolumn{3}{|c|}{ Body Weight } \\
\cline { 2 - 4 } & IBW & 20 & 99 \\
\hline $30-35$ & 77 & 30 & 68 \\
\hline $35-40$ & 90 & 20 & 69 \\
\hline $40-45$ & 70 & 29 & 78 \\
\hline $45-50$ & 66 & 40 & 70 \\
\hline $50-55$ & 79 & 39 & 72 \\
\hline $55-60$ & 60 & 40 & 40 \\
\hline $60-65$ & 50 & & < \\
\hline
\end{tabular}

Out of all 412 were mahadalit and daily wage earner while 794were of other categories Fig-3

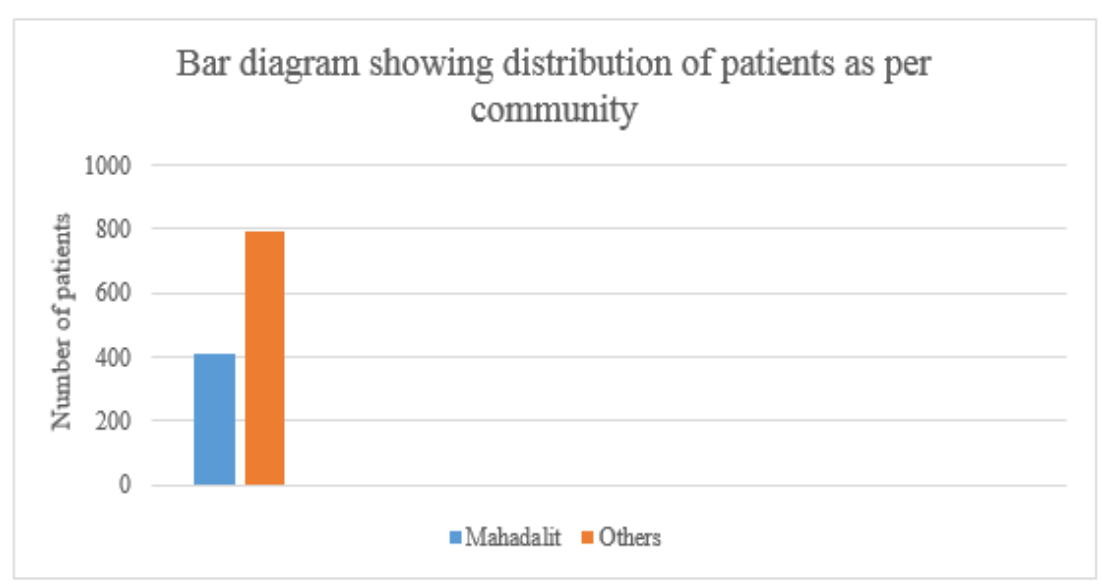

Figure3

$56 \%$ were with fasting blood sugar $>200 \mathrm{mg}$ and $50.2 \%$ with post prandial blood sugar $>300 \mathrm{mg} \% 85 \%$ shows altered hepatic enzymes (Table-7)

Table7. Distribution of patients as per their basic bio status

\begin{tabular}{|l|l|}
\hline Parameters & Number of Patients \\
\hline Blood Sugar & \\
\hline Fasting & 109 \\
\hline $120-140$ & 108 \\
\hline $140-160$ & 174 \\
\hline $160-180$ & 229 \\
\hline $180-200$ & 676 \\
\hline$>200$ & \\
\hline Post Prandial & 069 \\
\hline $200-230$ & 076 \\
\hline $230-260$ & 148 \\
\hline $260-290$ & 308 \\
\hline $290-320$ & 605 \\
\hline$>320$ & \\
\hline Hepatic Profile & \\
\hline SGOT & 182 \\
\hline$<35$ IU & 1024 \\
\hline$>35$ IU & \\
\hline SGPT & 180 \\
\hline$<35$ IU & 1026 \\
\hline$>35$ IU & \\
\hline Alkaline Phosphatase & 786 \\
\hline$<100$ IU/L & \\
\hline$>100$ IU/L & \\
\hline
\end{tabular}


Majority of study group (Group A) had marked and sustained decline in blood sugar with its bioregulation and progressive decline in dose of continuing antidiabetic drugs (OHA \& Insulin) with complete withdrawal of antidiabetic drugs in $62 \%$ of newly detected cases with normo glycaemic state during 2 years of rigorous follow up without any circadian variation while majority in control group(Group B) persisted with fasting blood sugar $>150 \mathrm{mg} \%$ and post Table8. Outcome of the Study prandial blood sugar $225 \mathrm{mg} \%$ even with similar dietary restriction and antidiabetic regime.

In addition all cases of study group achieved and retained normal hepatic and renal profile while control group $40 \%$ patients presented with altered hepato renal function in spite of progressive increase in dose of continuing antidiabetics(Table-8)

\begin{tabular}{|c|c|c|c|c|c|c|}
\hline \multirow[t]{3}{*}{ Particulars } & \multicolumn{6}{|c|}{ Number of Patients } \\
\hline & \multicolumn{3}{|c|}{ Group A } & \multicolumn{3}{|c|}{ Group B } \\
\hline & $1^{\text {st }}$ & $2^{\text {nd }}$ & $3^{\text {rd }}$ & $1^{\mathrm{st}}$ & $2^{\text {nd }}$ & $3^{\text {rd }}$ \\
\hline \multicolumn{7}{|l|}{ Blood Sugar } \\
\hline \multicolumn{7}{|l|}{ Fasting } \\
\hline$<100$ & 202 & 390 & 603 & - & - & 104 \\
\hline$>100$ & 401 & 211 & - & 603 & 603 & 499 \\
\hline \multicolumn{7}{|l|}{ Post Prandial } \\
\hline$<170$ & 202 & 390 & 603 & - & - & 104 \\
\hline$>170$ & 401 & 211 & - & 603 & 603 & 199 \\
\hline \multicolumn{7}{|l|}{ Hepatic Profile } \\
\hline \multicolumn{7}{|c|}{ SGOT } \\
\hline$<35 \mathrm{IU}$ & 124 & 399 & 603 & 91 & 102 & 103 \\
\hline$>35 \mathrm{IU}$ & 479 & 204 & - & 512 & 501 & 500 \\
\hline \multicolumn{7}{|l|}{ SGPT } \\
\hline$<35 \mathrm{IU}$ & 124 & 399 & 603 & 91 & 100 & 100 \\
\hline$>35 \mathrm{IU}$ & 479 & 204 & - & 512 & 503 & 503 \\
\hline \multicolumn{7}{|c|}{ Alkaline Phosphatase } \\
\hline$<100 \mathrm{IU} / \mathrm{L}$ & 244 & 512 & 603 & 242 & 298 & 291 \\
\hline$>100 \mathrm{U} / \mathrm{L}$ & 359 & 91 & - & 361 & 305 & 312 \\
\hline
\end{tabular}

\section{RESUlT}

Hepatogogue adjunction with dietary restriction bioregulate metabolic process and blood sugar without any circadian variation or untoward effect with continued tapering of continuing antidiabetics.

\section{DisCusSIONS}

Diabetes mellitus rampantly spreading disease was thought to be purely due to defunct pancreatic $\beta$ cell function ${ }^{(19,20)}$ and these days affecting hard workers and daily wage earner, considerably due to emergence of non-nutrients in routinely consumed diet and toxic substances which is not only affect the hepatic parenchyma and pancreas but also potentiate the Dipeptidyl peptidase 4 secretion and dampen the secretion of Glucagon like peptide I(GLP-I) and Glucose dependent Insulin tropics (GLI) in the small intestine.(Figure -4)

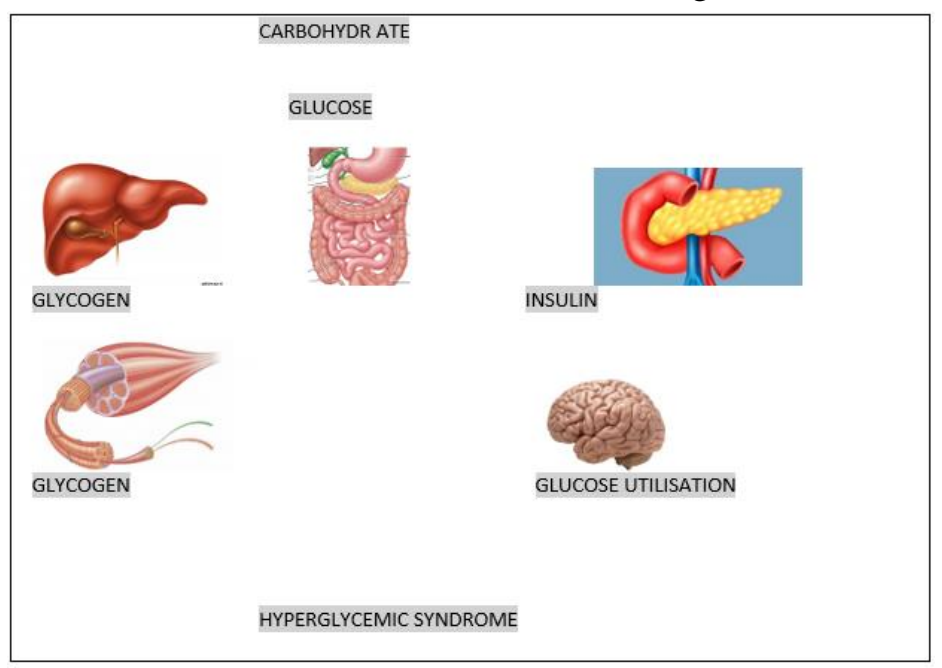

Figure4 
Altered hepatic parameters in majority detected cases and response of hep [apologue adjuvant with anti-diabetic therapy ensure decline in blood sugar with bioregulation and without circadian variation. Also prompted elimination of toxic non-nutrient of the diet and help suppression of Dipeptidyl peptidome 4 thus delays degradation of GLP and GIP ensuring insulin bio regulation and progressive decline in continuing anti diabetic drugs ${ }^{(21,22)}$ High sustainability to higher blood sugar is due to glucose un utilized by liver for Glycogenesis, thus this study affirms the hyperglycaemic manifestation as a combined effect of hepatic, pancreatic and intestine hormone dysfunction, secondly incidence in daily wage earner is due to consumption of similar cereals irrespective of the economic strata whose non-nutrient constituent affect alike. Hence to curb the disease and limit its progressive increase the prime step needed is

- Restrict first diet to 100 calories or $25 \mathrm{gm}$ of cereals

- Avoid use of rice, potato, sugar and poultry products

- Limit the use of fertilizer, chemical, hormones, pesticides and preservatives

- Prefer fresh food

- Remain stress less for which develop ignorance

\section{CONClusion}

The disease known for luxury these days also common among hard worker and daily wage earners due to altered production and secretion of GLP1 and GIP from L cells of mucosal lining of duodenum jejunum and small intestine. Patients of hyperglycaemia either fresh or old taking anti diabetic drugs show altered hepatic function and capacity to sustain its vitality even in a state of highly raised blood sugar. Adjuvant hepatogogue in either cases i.e., fresh or old shows marked decline in blood sugar with sustained normoglycemic state without any circadian variation of blood glucose, thus suggest these days hyperglycaemia as a combined effect of glucose conversion and glucose metabolism i.e. alteration in function of both liver and pancreas as a result of increasing non nutrients in diet and altered life style

\section{REFERENCES}

[1] World Health Organization, Global Report on Diabetes. Geneva, 2016. Accessed 30 August 2016.

[2] Williams textbook of endocrinology (12th ed.). Philadelphia: Elsevier/Saunders. pp. 13711435. ISBN 978-1-4377-0324-5.

[3] Agardh E et al., "Type 2 diabetes incidence and socio-economic position: a systematic review and meta-analysis." International Journal of Epidemiology 2011, 40(3): 804-818.

[4] Gale, Jason (November 7, 2010). "India's Diabetes Epidemic Cuts Down Millions Who Escape Poverty". Bloomberg. Retrieved 8 June 2012

[5] Wild S., et al. "Global prevalence of diabetesestimates for the year 2000 and projections for 2030". Diabetes Care 27.5 (2004): 1047-1053.

[6] Whiting Dr., et al. "IDF Diabetes atlas: Global estimates of the prevalence of diabetes for 2011 and 2030". Diabetes Research and Clinical Practice 94.3 (2011): 311-321.

[7] Anjana RM., et al. "The need for obtaining accurate nationwide estimates of diabetes prevalence in India - rationale for a national study on diabetes". Indian Journal of Medical Research 133 (2011): 369-380.

[8] Ramachandran A., et al. "Diabetes Epidemiology Study Group in India (DESI). High prevalence of diabetes and impaired glucose tolerance in India: National Urban Diabetes Survey". Diabetologia 44.9 (2001): 1094-1101.

[9] Arora V., et al. "Prevalence of diabetes in urban Haryana". Australasian Medical Journal 3.8 (2010): 488-494.

[10] ShankarA.et al; Dietary non nutrients posing Health hazards, Acta Scientifica Nutrition Health January 2018

[11] Shankar, A et all Effect of initial Dietary Dose on Therapeutic response and quality of life in Diabetes Mellitus Acta Scientifica Nutrition Health July 2018.

[12] "Diabetes can be controlled in 80 percent of Cases in India". IANS.news.biharprabha.com. Retrieved 6 February 2014.

[13] Kleinfield, N. R. (September 13, 2006). "Modern Ways Open India's Doors to Diabetes". New York Times. Retrieved 8 June 2012.

[14] Kumar A., et al. "India towards diabetes control: Key issues". Australasian Medical Journal 6.10 (2013): 524-531.

[15] Sukala WR., et al. "Exercise intervention in New Zealand Polynesian peoples with type 2 diabetes: Cultural considerations and clinical trial recommendations". Australasian Medical Journal 5.8 (2012): 429-435. 
[16] Mohan V., et al. "Current status of management of diabetes and glycaemic control in India: Preliminary results from the DiabCare India 2011 Study". Diabetes 61 (2012): a645-a677. Conclusion 65

[17] Donnelly D. "Structure and function of GLP 1 and its ligands". British Journal of Pharmacology 166.1 (2012): 21-41.

[18] Unnikrishnan RI., et al. "Importance of Controlling Diabetes Early-The Concept of Metabolic Memory, Legacy Effect and the Case for Early Insulinisation". Journal of the Association of Physicians of India 59 (2011): 812.
[19] Verma R., et al. "National programme on prevention and control of diabetes in India: Need to focus". The Australasian medical journal 5.6 (2012): 310-315.

[20] State-based diabetes prevention and control program. Centers for Disease Control and Prevention. U.S Department of Health and Human Services (2013).

[21] National Diabetes Education Program. Centers for Disease Control and Prevention (2013).

[22] Bramley D., et al. "Indigenous disparities in disease-specific mortality, a cross-country comparison: New Zealand, Australia, Canada, and the United States". The New Zealand Medical Journal 117.1207 (2004): U1215.

Citation: Dr Avinash Shankar, Dr Amresh Shankar, Dr Anuradha Shankar, Diabetes Mellitus Management, Needs Reconsideration. ARC Journal of Clinical Case Reports. 2019; 5(2): 18-25. doi:dx.doi.org/10.20431/ 2455-9806.0502004.

Copyright: (C) 2019 Authors. This is an open-access article distributed under the terms of the Creative Commons Attribution License, which permits unrestricted use, distribution, and reproduction in any medium, provided the original author and source are credited. 